\title{
Incompatibilidade somática em Rhizoctonia solani AG-1 IA da soja
}

\author{
Ana Paula da Silva de Campos ${ }^{1}$ e Paulo Cezar Ceresinini,
}

\begin{abstract}
${ }^{1}$ Faculdade de Engenharia (FEIS) - Campus de Ilha Solteira, UNESP, Dept. Fitoss., Eng. Rural e Solos, FEIS/UNESP
${ }^{2}$ Swiss Federal Institute of Technology - ETHZ, Institute of Integrative Biology, LFW B28, 8092 Zurich, Switzerland, e-mail: paulo.ceresini@agrl.ethz.ch

Data de chegada 30/07/2004. Aceito para publicação em: 30/03/2006.
\end{abstract}

\section{ABSTRACT}

Campos A. P. S.; Ceresini P. C. Somatic incompatibility in Rhizoctonia solani AG-1 IA of soybean. Summa Phytopathologica. v32, n.3, p.247-254, 2006.

Rhizoctonia solani anastomosis group 1 IA (AG-1 IA) is considered one of the most important pathogens affecting soybean in Brazil, causing the aerial or foliar blight. This disease is associated with the teleomorphase of $R$. solani AG-1 IA, the basidiomycete fungus Thanatephorus cucumeris. In this study, based on previous knowledge of the biology of $R$. solani AG-1 IA, two hypotheses were tested. In the first we postulated the occurrence of somatic incompatibility in populations of $R$. solani AG-1 IA. The second was that the population of $R$. solani AG1 IA from soybean has a clonal structure. Two population samples of R. solani AG-1 IA from soybean, obtained in Maranhão and Mato Grosso were analyzed. In the first sample, isolates with distinct RAPD (Random Amplified Polymorphic DNA) profile were selected to maximize the genetic diversity of isolates and to avoid the introduction of clones in the assay. The isolates were paired in all possible combinations in PDA plus charcoal medium and examined according to the resulting somatic interactions. Six somatic compatibility groups (SCG) were detected among
24 isolates of AG-1 IA. However, microscopic analyzes of the pairings indicated higher frequency of somatic incompatibility, resulting in the impossibility of grouping any two isolates of $R$. solani AG-1 IA into SCG. In general, the methodology for evaluating the macroscopic somatic interactions in PDA plus charcoal medium seemed not totally appropriate for discriminating between categories of somatic compatibility amongst isolates of $R$. solani AG-1 IA. With the second sample of isolates we aimed to determine the occurrence of clones in the population of the pathogen, i.e., isolates that share the same phenotypic RAPD profile and are somatically compatible. Considering the range of somatic interactions between pairings of $R$. solani AG-1 IA isolates and the deviations of the strict association between the GCS detected and the RAPD profile formerly observed by Fenille (11) and Meyer (20) are consistent with recombination. However, there is evidence for an expressive clonal component in the population. From a total of 43 isolates of $R$. solani AG-1 IA, 16 were probable clones.

Additional key words: clonality, population structure.

\section{RESUMO}

Campos A. P. S.; Ceresini P. C. Incompatibilidade somática em Rhizoctonia solani AG-1 IA da soja. Summa Phytopathologica. v32, n.3, p.247-254, 2006

O fungo Rhizoctonia solani AG-1 IA é um dos patógenos mais importantes que afeta a cultura da soja no Brasil, causando a mela ou queima foliar. A doença está associada com a fase teleomórfica de $R$. solani, o basidiomiceto Thanatephorus cucumeris. Neste estudo, baseando em conhecimento prévio sobre a biologia de $R$. solani AG-1 IA, duas hipóteses foram testadas. Na primeira hipótese postulou-se a ocorrência de incompatibilidade somática em populações de $R$. solani AG-1 IA. A segunda hipótese testada foi de que esta população de $R$. solani AG-1 IA da soja apresenta indicações de estrutura sexual clonal. Duas amostras de isolados de R. solani AG-1 IA da soja obtidas no Maranhão e no Mato Grosso foram utilizadas. Na primeira amostra, foram selecionados isolados apresentando diferentes perfis de RAPD (Random Amplified Polymorphic DNA), procurando maximizar a diversidade dos isolados, e evitando a introdução de possíveis clones no teste. Os isolados foram pareados em todas as combinações possíveis em meio de BDA mais carvão ativado e examinados quanto às interações somáticas resultantes. Seis grupos de incompatibilidade somática (GCS) foram detectados entre 24 isolados do AG-1 IA. Entretanto, análises microscópicas dos pareamentos entre isolados indicaram maior freqüência de incompatibilidade somática, impossibilitando o grupamento em GCS. No geral, a metodologia de avaliação das interações somáticas macroscópicas em meio BDA + carvão ativado, não se mostrou totalmente apropriada para discriminação das categorias de reações de compatibilidade entre isolados de $R$. solani AG-1 IA. Com a segunda amostra procurou-se determinar a ocorrência de clones na população do patógeno, ou seja, isolados que compartilham o mesmo padrão fenotípico de RAPD e somaticamente compatíveis. No caso de R. solani AG -1 IA da soja, a gama de interações somáticas entre pareamentos de isolados e, principalmente, os desvios na associação estrita entre os GCS detectados neste trabalho, conjuntamente com os perfis de RAPD observados anteriormente por Fenille (11) e Meyer (20), são consistentes com recombinação. Entretanto, o patógeno ainda apresenta um componente clonal expressivo na população. De um total de 43 isolados, os exemplos de prováveis clones na população do patógeno totalizaram 16 isolados.

Palavras-chave adicionais: clonalidade, estrutura de populações. 


\section{Introdução}

O fungo habitante do solo Thanatephorus cucumeris (Frank) Donk [anamorfase $=$ Rhizoctonia solani Kühn] é um basidiomiceto que ocorre mundialmente causando doenças economicamente importantes em uma grande variedade de plantas cultivadas $(2,4,25)$. A maioria dos isolados deste patógeno não se reproduz sexuadamente e são conhecidos apenas por seu estágio assexual (anamorfase). Os isolados de $R$. solani são classificados de acordo com grupos de anastomose (AGs) baseando-se na ocorrência de fusão de hifas (anastomose) com isolados padrões de AGs designados. Isolados de diferentes AG geralmente não são capazes de fundir hifas entre si, indicando que AGs são geneticamente isolados. Este conceito foi solidificado por dados de hibridização DNA/ DNA (27), sequenciamento das regiões do ITS (Internal Transcibed Spacer) e da subunidade 28S do DNA ribossômico nuclearmente codificadas (12).

O grupo de anastomose 1-IA (AG1-IA) é um dos patógenos mais importantes afetando a cultura da soja no mundo. Este fungo causa queima da folha e/ou mela em soja (15). A mela está frequentemente associada à fase teleomórfica ou sexuada do fungo (T. cucumeris). Em determinados estados brasileiros onde as condições ambientais são favoráveis para o patógeno (como Maranhão, Mato Grosso, Piauí, Tocantins, Pará e Roraima), perdas causadas pela mela podem variar de 31 a $60 \%(19,30)$.

Para isolados dos poucos AGs de T. cucumeris que esporulam "in vitro", a genética da sexualidade tem sido estudada analisando-se a formação de tufos heterocarióticos (condição em que um micélio contém dois núcleos geneticamente diferentes por célula) na área de contato entre culturas de isolados monobasidiospóricos (culturas do fungo obtidas a partir de um único basidiósporo, o qual é haplóide; o homocário) (1, 4, 16, 28). No momento, apenas a genética da sexualidade dos AG1-IC e AG4 são, até certo ponto, compreendidas, mostrando que isolados de campo desses AGs são heterocarióticos e bipolares (tipo de sexualidade em que os fatores de compatibilidade para cruzamento são de dois tipos apenas; também denominado heterotalismo bipolar; neste caso, para que dois homocários sejam sexualmente compatíveis, é necessário que possuam diferentes alelos no locus que controla o cruzamento sexual) $(9$, 17). Muito pouco se sabe sobre o sistema de cruzamento sexual dos demais AGs de T. cucumeris. Por sua vez, o isolamento genético dos AGs e as diferenças potenciais na sexualidade requerem análise genética separada para cada AG.

Informação prévia sobre o sistema de cruzamento ou sobre a estrutura de populações de $R$. solani podem ser obtidas pela análise da associação entre marcadores genéticos independentes (7). Por exemplo, uma progênie gerada via reprodução sexual homotálica (auto-fértil) será geneticamente idêntica (ou quase idêntica) aos isolados parentais e todas as partes do genoma terão a mesma história evolucionária, devido à ausência de recombinação $(26,29)$. Dependendo da idade da população, nenhuma ou limitada recombinação genética contribuiria para a associação entre caracteres independentes (marcadores genéticos). Dessa forma, uma população com diversidade genética limitada e identificação repetida de genótipos similares indicam estrutura populacional clonal.
Em contraste, progênie gerada através de reprodução sexual heterotálica (auto-estéril) será geneticamente diferente dos isolados parentais, como resultado da recombinação de núcleos geneticamente diferentes. Assim, regiões diferentes do genoma da progênie terão histórias evolucionárias diferentes (26). Neste caso, a recombinação reduziria (ou eliminaria) a associação estrita um-para-um entre caracteres independentes e resultaria em uma estrutura populacional não clonal $(3,10,21)$. Comumente, a incompatibilidade somática e marcadores moleculares são usados como dois critérios independentes para inferência inicial sobre os sistemas de cruzamento e a estrutura predominante em populações de $R$. solani (7). Embora haja informação sobre diversidade genética de isolados de populações de campo de $R$. solani AG-1 IA através de marcadores RAPD (14), não há estudos sobre estrutura de populações de $R$. solani AG-1 IA baseados na associação entre caracteres independentes.

Neste estudo, foram testadas duas hipóteses. Na primeira hipótese postulou-se a ocorrência de incompatibilidade somática em populações de $R$. solani AG-1 IA. Para tal, amostras de isolados de $R$. solani AG-1 IA (com padrão distinto de RAPD) obtidos em Mato Grosso e no Maranhão foram pareadas em meio de cultura e em lâmina de vidro e examinadas quanto às interações somáticas macroscópicas e microscópicas resultantes. A segunda hipótese testada foi que esta população de $R$. solani AG-1 IA da soja apresenta indicações de estrutura sexual clonal. Evidências de estrutura clonal foram investigadas, determinando se isolados que compartilham o mesmo padrão fenotípico de RAPD são somaticamente compatíveis. Os padrões fenotípicos de RAPD dos isolados foram previamente determinado por Fenille (11) e Meyer (20). Este estudo estabelece os fundamentos iniciais para o exame da estrutura genética de populações de $R$. solani AG-1 IA.

\section{MATERIALEMÉTODOS}

Isolados-Os isolados de $R$. solani AG-1 IA causadores de mela em soja foram gentilmente cedidos por R. C. Fenille e M. C. Meyer (obtidos da micoteca da Faculdade de Ciências Agronômicas - UNESP - Câmpus de Botucatu). A relação e a distribuição regional da origem dos isolados estão descritas na Tabela 1. Os isolados foram caracterizados através de técnicas citomorfológicas e culturais clássicas para identificação de grupos de anastomose, através de marcadores RAPD, do sequenciamento das regiões ITS-5.8S rDNA e quanto à patogenicidade $(11,20)$. Os isolados vem sendo mantidos a $20^{\circ} \mathrm{C}$ em grãos de arroz esterilizados.

Determinação de grupamentos de compatibilidade somática. Baseando-se em informação prévia sobre o perfil de RAPD dos isolados determinado por Fenille (11) e Meyer (20), selecionou-se uma amostra de 24 isolados de soja obtida em Mato Grosso e no Maranhão. Para maximizar diferenças na compatibilidade somática, optou-se por isolados pertencentes a grupos distintos de RAPD. A amostra final compôs-se de 18 isolados de grupos distintos de RAPD e seis de mesmo grupo (SJ051 e SJ056 do grupo FG3-F, SJ058 e SJ078 do grupo FG 6 e SJ123 e SJ127 do grupo MG1-E). Os isolados utilizados neste primeiro estudo aparecem em negrito na Tabela 1. 
Tabela 1. Isolados de Rhizoctonia solani AG-1 IA da mela da soja disponíveis na Micoteca do Departamento de Fitossanidade, Engenharia, Rural e Solos, UNESP-Câmpus de Ilha Solteira.

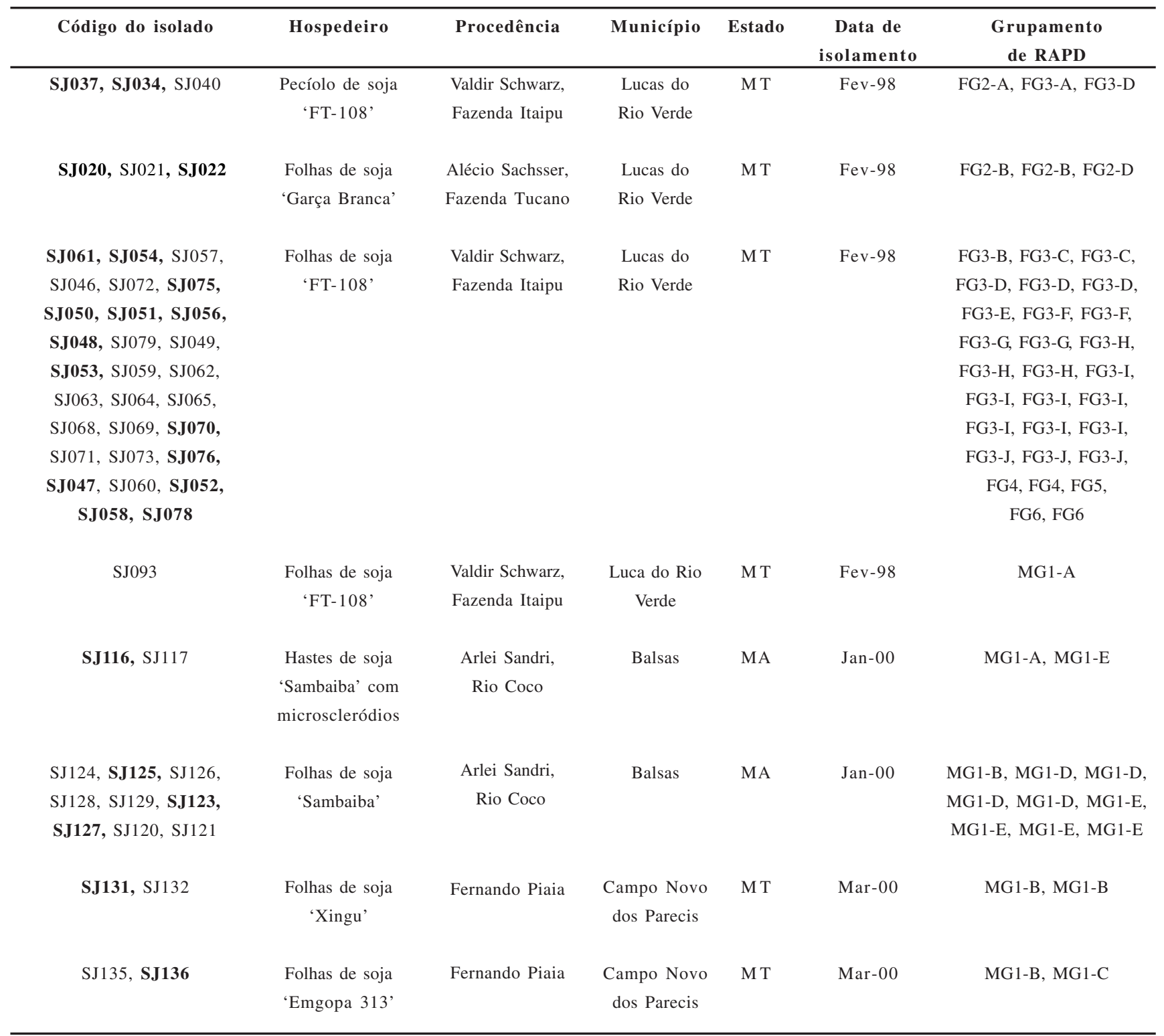

*Isolados gentilmente cedidos pelos Drs. R.C. Fenille e M.C. Meyer (Faculdade de Ciências Agronômicas - UNESP - Câmpus de Botucatu).

Para reativação das culturas, os isolados de $R$. solani AG-1 IA conservados a -20C em grãos de arroz esterilizados foram transferidos para placas de Petri contendo meio de batata dextrose ágar (Difco® PDA a 3\%), conforme Ceresini et al. (7). A seguir, os 24 isolados do AG-1 IA foram transferidos e pareados em todas as combinações possíveis em meio BDA suplementado com carvão ativado a $1 \%$ (5), de acordo com o procedimento de Macnish et al. (18). A disposição dos discos contendo micélio dos isolados no meio durante os pareamentos é apresentada na Figura 2. Os isolados foram incubados por 4 dias a $25^{\circ} \mathrm{C}$ e as interações somáticas entre isolados foram determinadas macroscopicamente.
Os pareamentos foram considerados somaticamente compatíveis quando nenhuma reação foi observada na linha de contato entre pares de isolados. Os pareamentos foram considerados somaticamente incompatíveis quando se observou reação caracterizada por tufos de hifas na linha de contato entre pares de isolados. Reações do tipo fraca entre isolados foram também observadas. Essas reações foram caracterizadas pela formação de tufos de hifas pouco densos na linha de contato entre isolados, como relatado por Macnish et al. (18) e Ceresini et al. (8). O experimento de incompatibilidade somática foi conduzido uma vez efetuandose um total de 1656 pareamentos (24 isolados pareados entre 
si em todas as possíveis combinações e cada pareamento repetido três vezes).

Em virtude da simplicidade das observações fenotípicas detectadas para o conjunto de isolados selecionados do AG1 IA, na determinação de grupos de compatibilidade somática (GCS), propôs-se à construção de uma matriz simples de dados de compatibilidade.

Para confirmar as observações macroscópicas de incompatibilidade somática efetuadas na primeira etapa do trabalho, repetiu-se o experimento utilizando o teste microscópico de compatibilidade somática através do pareamento de isolados em lâmina de vidro, com a observação das categorias de reação de anastomose entre pares de isolados. Estes pareamentos foram determinados microscopicamente em lâminas de vidro contendo uma camada fina do meio ágar-água (AA) a 1,5\% e 1,5 mL.L $\mathrm{L}^{-1}$ do corante de alimentos McCormick $(13,14)$. As categorias de reações de anastomoses de hifas foram examinadas de acordo com Carling (6), como se segue: C2 ou somaticamente incompatível, indicando que os isolados pertencem ao mesmo grupo de anastomose, mas a diferentes GCS; e C3 ou somaticamente compatível, indicando isolados bastante relacionados (do mesmo grupo de anastomose, do mesmo GCS, ou o mesmo indivíduo).

Busca de indícios de estrutura clonal. Para determinar se a população de $R$. solani AG-1 IA da soja apresenta indicações de estrutura clonal, observou-se a associação constante entre dois caracteres distintos: compatibilidade somática e padrão fenotípico de RAPD. Dessa forma, procurou-se determinar se os isolados somaticamente compatíveis compartilhavam o mesmo padrão fenotípico de
RAPD. Para tanto, foram selecionados 14 grupos distintos de isolados quanto ao padrão fenotípico de RAPD. Neste experimento foram pareados apenas isolados com padrão fenotípico comum de RAPD. A compatibilidade somática entre isolados foi determinada através de interações somáticas macroscópicas (em meio de BDA suplementado com carvão ativado a 1\%) e microscópicas (em lâminas de vidro contendo meio AA a $1,5 \%+1,5$ mL.L $\mathrm{L}^{-1}$ do corante de alimentos McCormick). As categorias de interações somáticas macroscópicas e microscópicas (anastomose de hifas) foram analisadas como descritas anteriormente.

\section{RESULTADOSE DISCUSSÃO}

O principal objetivo deste estudo foi examinar a diversidade de grupos de compatibilidade somática de $R$. solani AG -1 IA no Brasil.

Por meio de interações somáticas macroscópicas apenas seis GCS foram identificados na amostra de $R$. solani AG-1 IA da soja. Todos os seis grupos de compatibilidade somática do AG-1 IA, estiveram associados com mais de um perfil de RAPD, uma vez que 22 fenótipos distintos de RAPD compunham esta amostra de 24 isolados. O agrupamento fenotípico de isolados de AG -1 IA, baseado em reações macroscópicas de incompatibilidade somática, é apresentado na Figura 1.

Entre os GCS identificados, o GCS A foi composto por dois isolados compatíveis entre si: SJ20 e SJ22. Já o GCS B compôsse de 16 isolados, todos do MT: SJ034, SJ037, SJ047, SJ048, SJ050, SJ051, SJ052, SJ053, SJ054, SJ056, SJ058, SJ061, SJ070, SJ075, SJ076 e SJ078. O GCS C foi composto pelos isolados SJ116 e SJ136 e o GCS D pelos isolados SJ123 e SJ127. Os

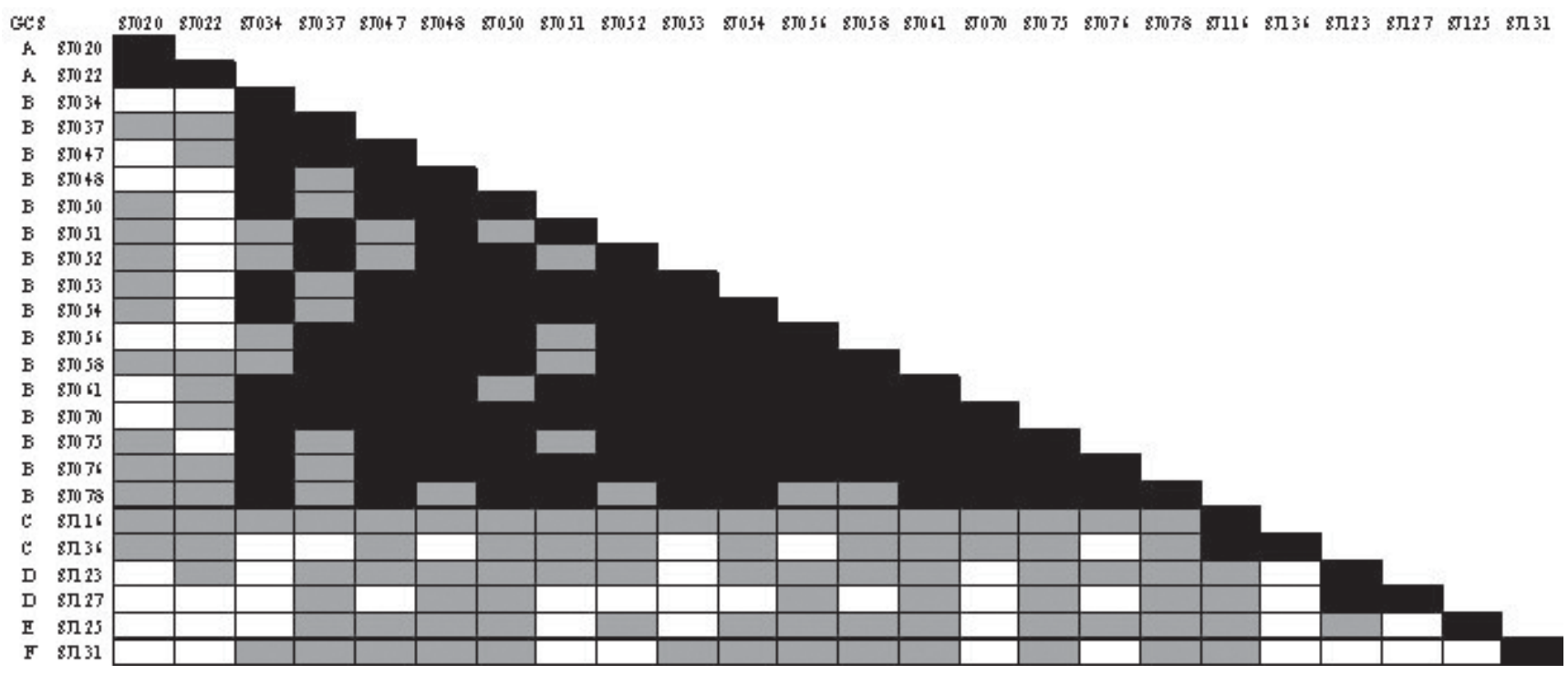

Figura 1. Interações somáticas macroscópicas entre isolados de Rhizoctonia solani AG-1 IA da soja. As categorias de interações somáticas macroscópicas foram: $\quad$ somaticamente compatíveis, quando nenhuma reação foi observada na linha de contato entre pares de isolados; $\square$ somaticamente incompatíveis, quando se observou reação caracterizada por tufos de hifas na linha de contato entre pares de isolados; $\square$ reações de incompatibilidade do tipo fraca entre isolados (MACNISH et al. (18); CERESINI et al.(8)). 

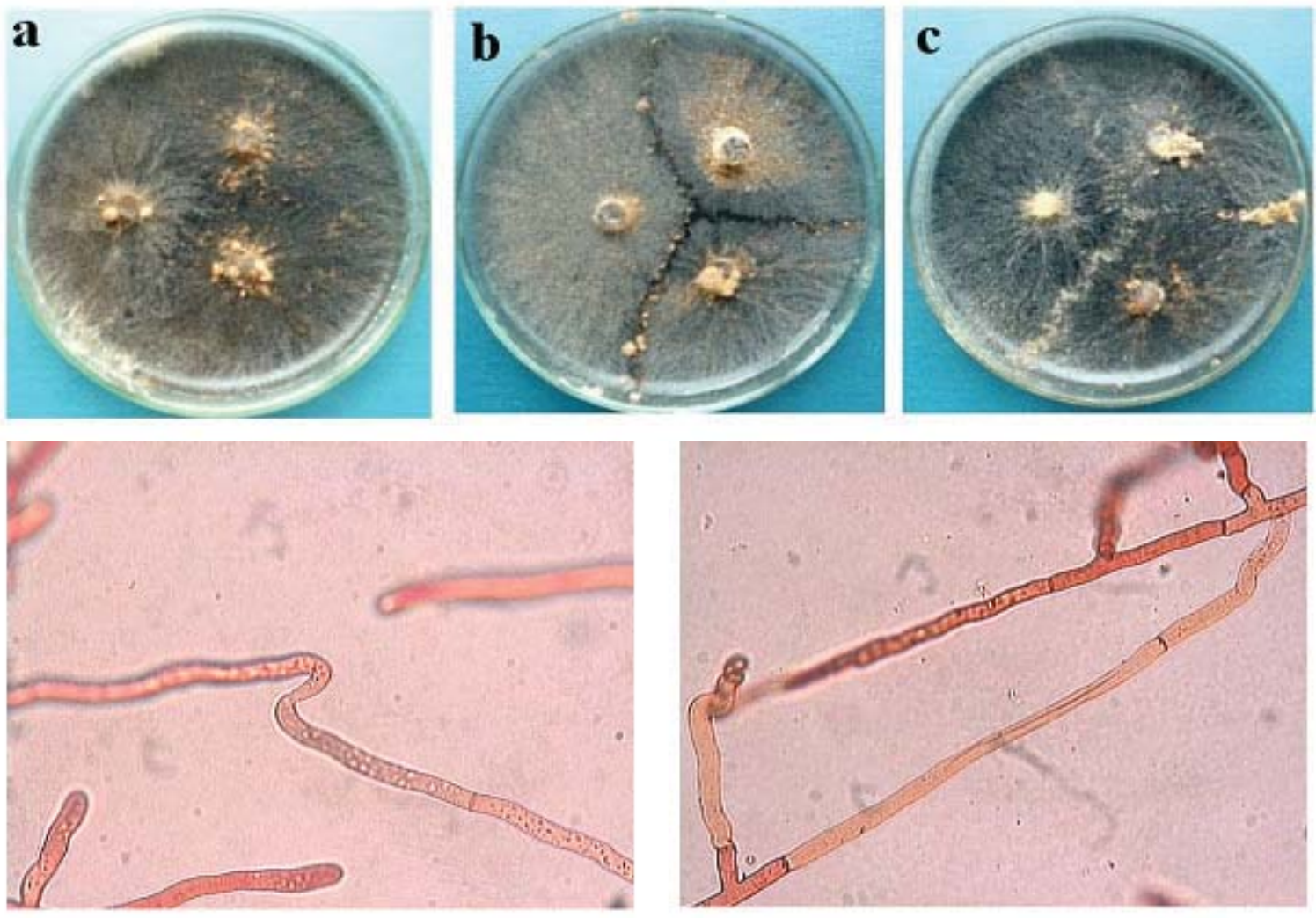

Figura 2. Interações somáticas macroscópicas e microscópicas entre isolados de Rhizoctonia solani AG-1 IA da soja: a) interação somaticamente compatível (nenhuma demarcação distinta na zona de interação das hifas entre isolados pareados); b) interação somaticamente incompatível (demarcação clara entre isolados pareados), c) interação incompatível fraca (demarcação pouco clara entre isolados pareados) d) reação microscópica do tipo C3 ou somaticamente compatível, que indica isolados bastante relacionados, o mesmo grupo de anastomose, o mesmo GCS, ou o mesmo indivíduo, e) reação microscópica $\mathrm{C} 2$ ou somaticamente incompatível, que indica que os isolados pertencem ao mesmo grupo de anastomose, mas a diferentes GCS.

demais isolados (SJ125 e SJ131) foram incompatíveis com todos os demais, constituindo grupos independentes: GCS E e o GCS $\mathrm{F}$, respectivamente.

Com exceção dos isolados SJ116 (do MA) e SJ136 (do MT), ambos pertencentes ao GCS C, nenhum outro isolado do MT foi compatível com os isolados do MA. Nas amostras dos dois estados foram detectados quatro GCS no MT e três no MA: GCS A e B no MT, GCS C em ambos, GCS D e E no MA, e GCS F no MT.

Não houve caso de intransitividade, isto é, quando um isolado de um determinado GCS é somaticamente compatível com outro isolado pertencente a um distinto GCS.

Reações incompatíveis fracas foram observadas entre isolados de $R$. solani AG-1 IA, e corresponderam a 21,74 \% do total de pareamentos. Essas reações foram caracterizadas por pequenas áreas salientes na linha de interação micelial, que variaram em intensidade. As três categorias de interações somáticas macroscópicas entre isolados de $R$. solani AG-1 IA da soja são ilustradas na Figura 2. Fatores tais como, a relação genética dos isolados em interação, a idade do micélio e a distância de pareamento podem ser responsáveis pela variação na intensidade das interações macroscópicas entre hifas.
Entretanto, a significância biológica dessas reações macroscópicas fracas de incompatibilidade é desconhecida (7).

Com base nas observações sobre interações somáticas entre isolados de $R$. solani AG-1 IA da soja, a primeira hipótese sobre ocorrência de incompatibilidade somática foi aceita.

Numa segunda etapa desta pesquisa, buscou-se confirmar as observações macroscópicas através de análises microscópicas das interações entre isolados de $R$. solani AG-1 IA. As categorias de reações microscópicas estão apresentadas na Figura 2 (d e e). Por meio das análises microscópicas dos pareamentos entre isolados que apresentavam diferentes perfis de RAPD, observou-se maior frequiência de incompatibilidade somática em relação às análises macroscópicas (Figura 3). Cerca de $43 \%$ das reações microscópicas entre isolados de $R$. solani AG-1 IA foram incompatíveis, enquanto que apenas $18 \%$ das reações foram consideradas incompatíveis macroscopicamente. Em função dessa maior freqüência de incompatibilidade somática observada pela análise microscópica, não foi possível agrupar isolados de $R$. solani AG-1 IA em GCSs. Praticamente cada um dos 24 isolados de $R$. solani AG-1 IA apresentou um perfil distinto de compatibilidade somática quando comparado com qualquer outro isolado. Mesmo aqueles isolados de $R$. solani 


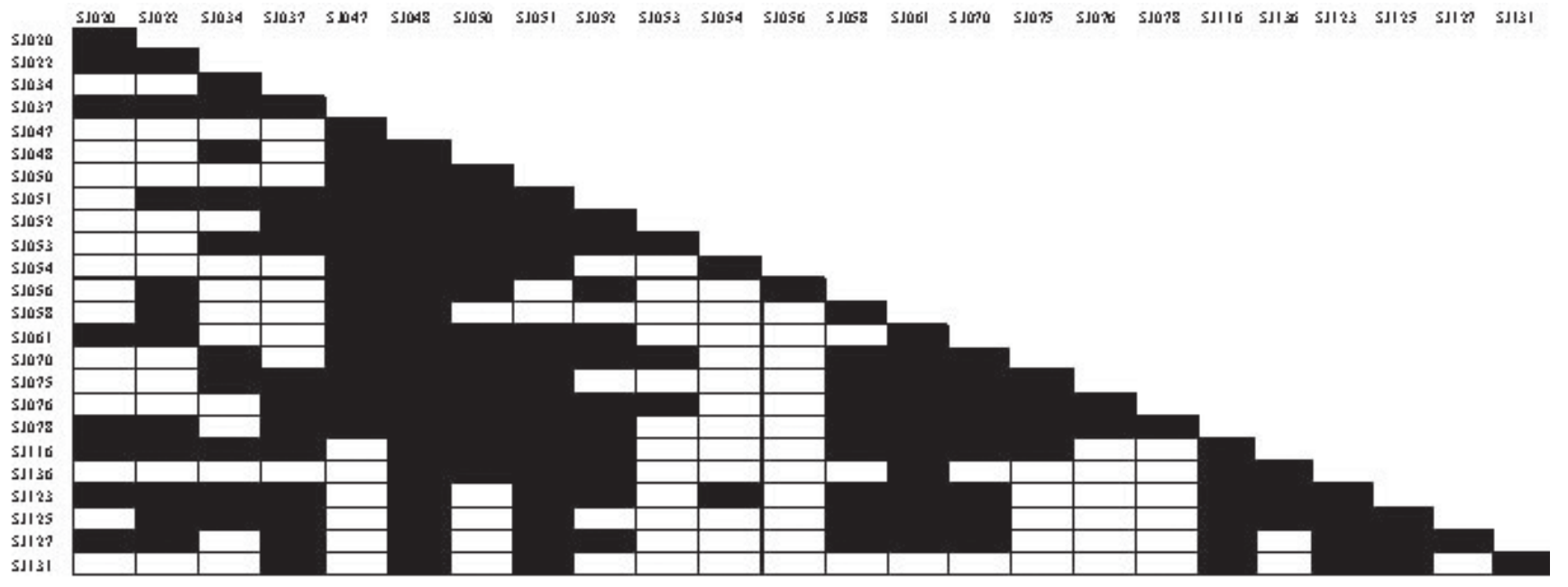

Figura 3. Interações somáticas microscópicas entre isolados de Rhizoctonia solani AG-1 IA da soja. As categorias de interações somática microcópicas (reações de anastomoses de hifas) foram examinadas de acordo com Carling (6), como se segue:

(C2 ou incompatível), que indica que os isolados pertencem ao mesmo grupo de anastomose mas a diferentes grupos de compatibilidade somática (GCS); e (C3 ou compatível), que indica isolados bastante relacionados, o mesmo grupo de anastomose, o mesmo GCS, ou o mesmo indivíduo.

AG-1 IA com mesmo perfil de RAPD (que representavam seis isolados na amostra), embora compatíveis entre si, diferiram quanto à compatibilidade com os demais isolados testados.

No geral, as interações microscópicas não reproduziram as observações das interações macroscópicas entre isolados de R. solani AG-1 IA. Por exemplo, $28 \%$ das reações macroscópicas consideradas compatíveis em meio de BDA + carvão ativado foram observadas como incompatíveis microscopicamente. Exemplos de reações entre isolados de $R$. solani AG-1 IA, anteriormente consideradas compatíveis através das análises macroscópicas e que foram observadas como incompatíveis microscopicamente, são as seguintes: SJ034 pareado com os isolados SJ047, SJ050, SJ054, SJ061, SJ076 e SJ078; SJ037 com SJ047, SJ056, SJ058, SJ061 e SJ070; SJ050 com SJ058; SJ052 com SJ054, SJ058 e SJ075; SJ053 com SJ054, SJ056, SJ058, SJ061, SJ075 e SJ078; SJ054 com SJ056, SJ058, SJ61, SJ070, SJ075, SJ076 e SJ078; SJ056 com SJ058, SJ061, SJ070, SJ075 e SJ076 e SJ058 com SJ061.

Também, reações incompatíveis pela análise macroscópica foram compatíveis quando analisadas microscopicamente (num total de $40 \%$ das reações incompatíveis macroscopicamente). Neste caso pode-se citar: SJ020 pareado com os isolados SJ123 e SJ127; SJ022 com SJ051, SJ056, SJ0125 e SJ127; SJ034 com SJ123 e SJ125; SJ048 com SJ136; SJ051 com SJ125, SJ127 e SJ131; SJ052 com SJ0127; SJ058 com SJ127; SJ070 com SJ123, SJ125 e SJ127; SJ123 com SJ131; SJ125 com SJ127 e SJ 131 e SJ136 com SJ123 e SJ125.

Há que se considerar também que as observações das interações somáticas microscópicas permitiram discriminar as reações de incompatibilidade macroscópica do tipo fraca que haviam representado $40 \%$ das reações observadas em meio de BDA + carvão ativado. Em termos das reações consideradas incompatibilidade macroscópica do tipo fraca, $48,3 \%$ do total foi compatível enquanto que $51,7 \%$ foi incompatível em lâmina de vidro.
Considerando-se as observações acima, a metodologia de avaliação das interações somáticas macroscópicas em meio de BDA suplementado com carvão ativado a $1 \%$ (5), não se mostrou totalmente apropriada para discriminação das categorias de reações de compatibilidade entre isolados de $R$. solani AG-1 IA.

Macnish et al. (18) já haviam observado que, para alguns AGs de $R$. solani não foi possível observar correspondência satisfatória entre as interações somáticas macroscópicas e microscópicas. Dessa forma, embora a análise de interações microscópicas seja consideravelmente mais laboriosa, ela tornase necessária em situações como a observada para o AG-1 IA onde a correspondência entre interações macroscópicas e microscópicas foi no mínimo errática (ou seja, apenas 60 a 72\% de acertos).

A utilização de critérios independentes, tais como a incompatibilidade somática e a análise de marcadores moleculares como RAPD, pode proporcionar informação preliminar sobre sistemas de cruzamento em $R$. solani AG-1 IA, bem como sobre a estrutura de populações: clonal ou recombinante, como indicado por Worrall (27) e Taylor et al. (24). Assim, para responder à questão sobre ocorrência de estrutura clonal na população de $R$. solani AG -1 IA da soja, procurou-se determinar se isolados que compartilham o mesmo padrão fenotípico de RAPD, previamente determinado por Fenille (11) e Meyer (20), são somaticamente compatíveis.

Observou-se que cerca de 75,9\% das interações somáticas macroscópicas entre isolados com mesmo perfil de RAPD foram compatíveis (Figura 4). Apenas $24,1 \%$ dessas interações foram incompatíveis do tipo fraca. Entretanto, ao se considerar as interações somáticas microscópicas, as interações compatíveis entre isolados de mesmo padrão de RAPD representaram 34,5\% do total, enquanto que as interações incompatíveis representaram $65,5 \%$. Mais uma vez a análise das interações microscópicas parece ser mais adequada na discriminação entre isolados compatíveis ou não, comparado com a análise das 


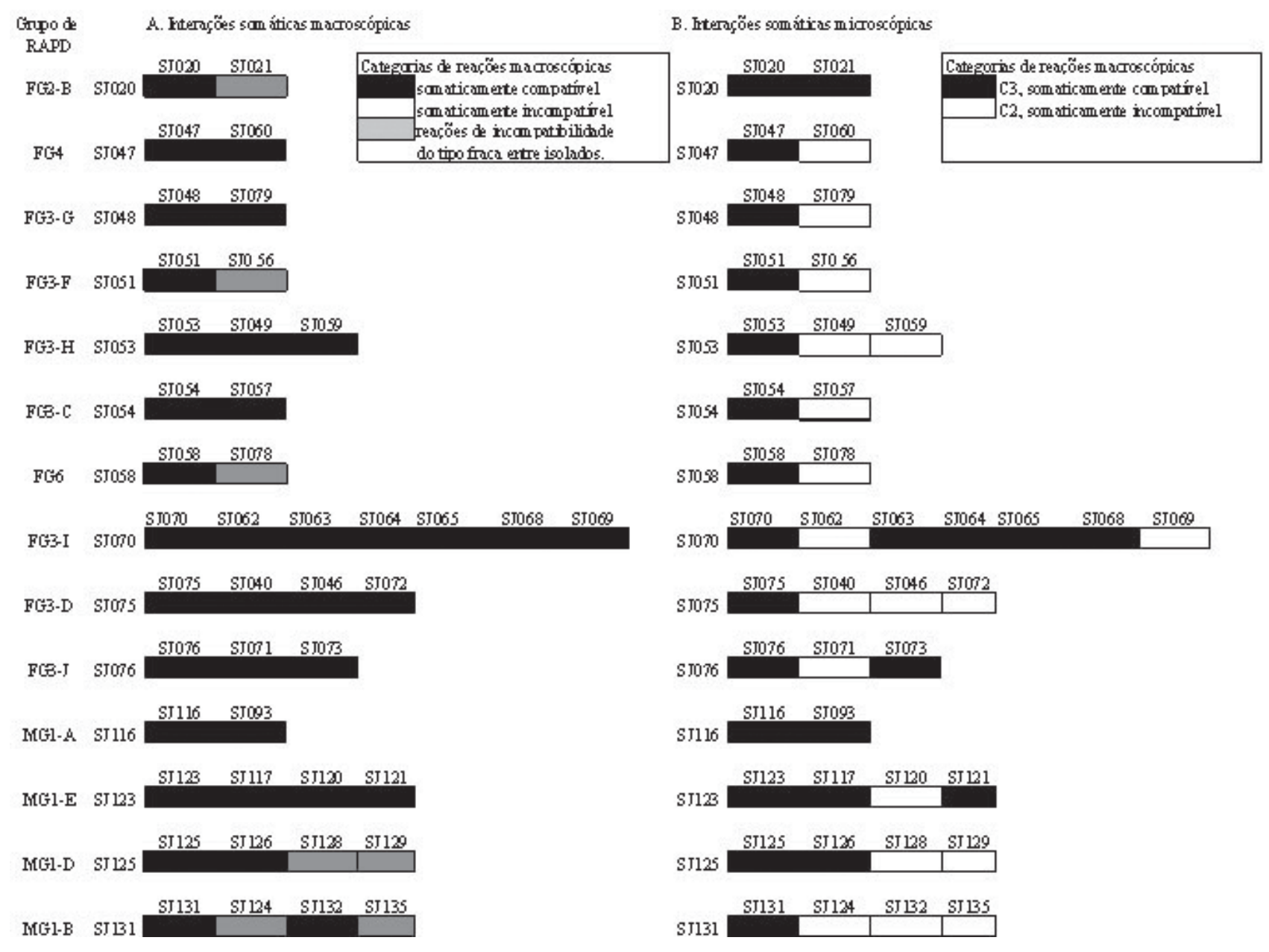

Figura 4. Interações somáticas macroscópicas (A) e microscópicas (B) entre isolados de Rhizoctonia solani AG-1 IA da soja dentro de grupos comuns de RAPD.

interações macroscópicas. Assim, considerando apenas as interações microscrópicas, é possível afirmar que a maioria dos isolados com mesmo perfil de RAPD não representam clones, pois são somaticamente incompatíveis. De um total de 43 isolados, os exemplos de prováveis clones na população do patógeno (ou seja, com mesmo perfil de RAPD e somaticamente compatíveis) são: SJ020 e SJ021 (FG2-B), SJ063, SJ064, SJ65, SJ068 e SJ-070 (FG3-I), SJ073 e SJ076 (FG3-J), SJ093 e SJ116 (MG1-A), SJ117, SJ121 e SJ123 (MG1-E), SJ125 e SJ126 (MG1-D). Estes últimos (clones) totalizam 16 isolados.

Este estudo ofereceu informação preliminar sobre a estrutura de populações de $R$. solani AG-1 IA da soja. A gama de interações somáticas entre pareamentos de isolados e, principalmente, os desvios na associação estrita entre os GCS detectados neste trabalho e os perfis de RAPD observados por Fenille (11) e Meyer (20) são consistentes com recombinação. Entretanto, o organismo ainda apresenta um componente clonal na população. Dessa forma, nossa segunda hipótese sobre a predominância de estrutura clonal na população de $R$. solani AG-1 IA não pode ser totalmente recusada. Evidências de clonalidade foram demonstradas para $R$. solani AG-1 IA no Texas, através de constante recuperação de genótipos semelhantes do patógeno em diferentes campos de arroz (22). Entretanto, análise da população usando dados corrigidos para clones indicou que quatro entre sete loci estavam em equilíbrio de Hardy-Weinberg e que apenas um entre todos os possíveis pares de loci estavam em desequilíbrio de ligação, o que indicou que a recombinação também estava ocorrendo (22).

Embora a estratégia de amostragem empregada neste estudo fosse, provavelmente, suficiente para maximizar a detecção de diversidade genética, amostragem adicional em áreas maiores é necessária para elucidar a magnitude da clonalidade e/ou da recombinação em populações locais do patógeno. Também, ainda não há informação sobre outras forças afetando a estrutura de populações de $R$. solani AG-1 IA, como a migração e o fluxo gênico. Entretanto, para estes estudos é necessário, inicialmente, o desenvolvimento de marcadores mais apropriados que os marcadores fenotípicos aqui utilizados. Por exemplo, o uso de um conjunto de marcadores genéticos codominantes, como aqueles baseados em PCR-RFLP, permitiriam discriminar 
melhor os genótipos do patógeno, inferir a ocorrência de recombinação baseando-se na ocorrência de equilíbrio de ligação entre alelos de loci distintos, bem como calcular a subdivisão de populações com base em diferenças nas freqüências alélicas.

\section{Agradecimentos}

Agradecemos a FAPESP pelo apoio financeiro através da concessão de auxílio para a realização deste trabalho (Processo 02/13752-6) e pela concessão de bolsa de IC para o primeiro autor (Processo 02/05024-0).

\section{REFERÊNCIASBIBLIOGRÁFICAS}

01. Adams, G.C. Jr.; Butler. E.E. A reinterpretation of the sexuality of Thanatephorus cucumeris anastomosis group four. Mycologia, New York, v.74, p.793-800, 1982.

02. Adams, G.C. Thanatephorus cucumeris (Rhizoctonia solani), a species complex of wide host range. Advances in Plant Pathology, London, v.6, p.535-552, 1988.

03. Anderson, J.B.; Kohn, L.M. Clonality in soilborne plant-pathogenic fungi. Annual Review of Phytopathology, Palo Alto, v.33, p.369391, 1995

04. Anderson, N.A. The genetics and pathology of Rhizoctonia solani. Phytopathology, St. Paul, v.20, p.329-344, 1982.

05. Butler E.E; Bolkan, H. A medium for heterokaryon formation in Rhizoctonia solani. Phytopathology, St. Paul, v.63, p.542-543, 1973.

06. Carling, D.E. Grouping in Rhizoctonia solani by hyphal anastomosis reaction. In: SNEH, B.; JABAJI-HARE, S.; NEATE, S.; DIJST, G. (Ed.) Rhizoctonia species: taxonomy, molecular biology, ecology, pathology and disease control. Dordrecht: Kluwer Academic, 1996. p.37-47.

07. Ceresini, P.C.; Shew, H.D.; Vilgalys, R.; Cubeta, M.A. Genetic diversity of Rhizoctonia solani AG-3 from potato and tobacco in North Carolina. Mycologia, Lawrence, v.94, n.3, p.448 - 460, 2002a.

08. Ceresini, P.C.; Shew, H.D.; Vilgalys, R.; Rosewich, U.L.; Cubeta, M.A. Genetic structure of populations of Rhizoctonia solani AG3 on potato in eastern North Carolina. Mycologia, Lawrence, v.94, n.3, p.437 - 447, 2002b.

09. Cubeta, M.A.; Briones-Ortega, R.; Vilgalys, R. Reassessment of heterokaryon formation in Rhizoctonia solani anastomosis group 4. Mycologia, Lawrence, v.85, p.777- 787, 1993.

10. Cubeta, M.A.; Vilgalys, R. Population biology of the Rhizoctonia solani complex. Phytopathology, St. Paul, v.87, p.480 484, 1997.

11. Fenille, R.C. Caracterização citomorfologica, cultural, molecular e patogênica de Rhizoctonia solani Kühn associado à soja no Brasil. 2001. 138f. Tese (Doutorado em Proteção de Plantas) - Faculdade de Ciências Agronômicas, Universidade Estadual Paulista, Botucatu.

12. Gonzales, D.; Carling, D.; Kuninaga, S.; Vilgalys, R.; Cubeta, M.A. Ribossomal DNA systematics of Ceratobasidium and Thanatephorus with Rhizoctonia anamorphs. Mycologia, Lawrence, v.93, p.1138-1150, 2001.

13. Gutierrez, W.A; Shew, H.D.; Melton, T.A. Sources of inoculum and management for Rhizoctonia solani damping-off on tobacco transplants under greenhouse conditions. Plant Disease, St. Paul, v.81, p.S35, 1998.

14. Herr, L.J.; Roberts, D.L. Characterization of Rhizoctonia solani populations obtained from sugar beet fields with differing soil textures. Phytopathology, St. Paul, v.70, p.476-480, 1980.

15. Jones, R.K.; Belmar, S.B. Characterization and pathogenicity of Rhizoctonia spp. Isolated from rice, soybean, and other crops grown in rotation with rice in Texas. Plant Disease, St. Paul, v. 73, p.1004-1010, 1989.

16. Julián, M.C.; Debets, F.; Keijer, J. Independence of sexual and vegetative incompatibility mechanisms of Thanatephorus cucumeris (Rhizoctonia solani) anastomosis group 1. Phytopathology, St. Paul, v.86, p.566-574, 1996.

17. Julián, M.C.; Acero, J.; Salazar, O.; Keijer, J. Marting typecorrelated molecuar markers and demonstration of heterokaryosis in the phytopathogenic fungis Thanatephorus cucumeris (Rhizoctonia solani) AG 1- IC by AFLP DNA finger printing analysis. Journal of Biotechnology, Amsterdam, v.67, p.49-56, 1999.

18. Macnish, G.C.; Carling, D.E; Brainard, K.A. Relationship of microscopic and macroscopic vegetative reactions in Rhizoctonia solani and the occurrence of vegetatively compatible populations (VCPs) in AG-8. Mycological Research, Cambridge, v.101, p.6168, 1997.

19. Meyer, M.C.; Yorinori, J.T. Incidência de doenças da soja em regiões tropicais. Documentos Embrapa Soja, Londrina, n.124, 1999.

20. Meyer, M.C. Caracterização de Rhizoctonia solani Kühn, agente causal da mela da soja [Glycine $\max (\mathrm{L}$.) Merril], seleção de genótipos e controle químico. 2001. 125 f. Tese (Doutorado em Proteção de Plantas) - Faculdade de Ciências Agronômicas, Universidade Estadual Paulista, Botucatu.

21. Milgroom, M.G. Recombination and the multilocus structure of fungal populations. Annual Review of Phytopathology, Palo Alto, v.34, p.457-477, 1996.

22. Rosewich, U.L.; Pettway, R.E.; Mcdonald, B.A.; Kistler, H.C. High levels of gene flow and heterozygote excess characterize Rhizoctonia solani AG-1 IA (Thanatephorus cucumeris) from Texas. Fungal Genetics and Biology, v.28, p.148-159, 1999.

23. Sneh, B.; Jabaji-Hare, S.; Neate, S.; Dijst, G. (Ed.) Rhizoctonia species: taxonomy, molecular biology, ecology, pathology and disease control. Dordrecht: Kluwer Academic, 1996. 578 p.

24. Taylor, J.W.; Jacobson, D.J.; Fisher, M.C. The evolution of asexual fungi: reproduction, speciation and classification. Annual Review of Phytopathology, Palo Alto, v.37, p.197-246, 1999.

25 . Vilgalys, R. Genetic relatedness among anastomosis groups in Rhizoctonia as measured by DNA/DNA hybridization. Phytopathology, St. Paul, v.78, p.698-702, 1988.

26. Whitney, H.S.; Parmeter, J.R. Synthesis of heterokaryons in Rhizoctonia solani Kühn. Canadian Journal Botany, Otawa, v.41, p.879-886, 1963.

27. Worrall, J.J. Somatic incompatibility in basidiomycetes. Mycologia, Lawrence, v.89, p.24-36, 1997.

28. Yorinori, J.T. Estratégias de controle das doenças da soja. Correio Agrícola, São Paulo, n.2, p.8-12, 1998. 